\title{
Mechanisms of Glioma Invasion: Role of Matrix-Metalloproteinases
}

\author{
J.H. Uhm, N.P. Dooley, J.-G. Villemure and V.W. Yong
}

\begin{abstract}
One of the most lethal properties of high grade gliomas is their ability to invade the surrounding normal brain tissue, as infiltrated cells often escape surgical resection and inevitably lead to tumour recurrence. The consequent poor prognosis and survival rate underscore the need to further understand and target the cellular mechanisms that underly tumour invasiveness. Proteases which degrade the surrounding stromal cells and extracellular matrix proteins have been demonstrated to be critical effectors of invasion for tumours of both central and peripheral origin. Within the nervous system, the role of metalloproteinases as well as other classes of proteases in mediating the invasive phenotype of high grade gliomas has been an intense area of research. We present in this article a review of this literature and address the possibility that these proteases and the biochemical pathways that regulate their expression, such as protein kinase $C$, may represent potential targets in the therapy of high grade gliomas.
\end{abstract}

\begin{abstract}
RÉSUMÉ: Mécanismes de l'invasion gliomateuse: rôle des métalloprotéinases matricielles. Une des propriétés les plus léthales des gliomes à haut degré de malignité est leur capacité d'envahir le tissu cérébral normal avoisinant, cette infiltration maligne échappant souvent à la résection chirurgicale, ce qui conduit inévitablement à la récidive tumorale. Le pronostic sombre et le taux de survie faible dé démontrent la nécessité de mieux comprendre et de cibler les mécanismes cellulaires sous-jacents au caractère envahissant de ces tumeurs. Il a été démontré que les protéases qui dégradent les cellules du stroma avoisinant et les protéines de la matrice extracellulaire sont des effectrices critiques de l'invasion par les tumeurs d'origine centrale et périphérique. Le rôle des métalloprotéinases et des autres classes de protéases dans la médiation de l'invasion du système nerveaux par les gliomes très malins a fait l'objet de recherches intenses. Nous présentons une revue de cette littérature et nous considérons la possibilité que ces protéases et les voies biochimiques qui régulent leur expression, telles la protéine kinase $\mathrm{C}$, pourraient être ciblées dans le traitment des gliomes de haut grade.
\end{abstract}

Can. J. Neurol. Sci. 1997; 24: 3-15

The hallmark of malignant tumours lies in their ability to invade the surrounding tissue, leading to the disruption of the architecture and ultimately to the dysfunction of the affected organ. This invasion process consists of a complex series of steps, involving alteration of the tumour cells' interaction with specific extracellular matrix (ECM) ligands, proteolysis of the matrix by hydrolytic enzymes, and subsequent migration of the cells through the degraded structures. ${ }^{1-3}$ Of the many discrete events, the capacity of the tumour cells to enzymatically digest their surrounding stroma and matrix best characterizes the invasive phenotype.

To effect degradation of the surrounding cellular and proteinaceous structures, malignant cells utilize one or more classes of proteolytic enzymes. The important role of proteases in the invasive process has been demonstrated in tumours of virtually every tissue-type ${ }^{3-6}$ Specifically in the nervous system, proteases have been strongly implicated as mediators of the invasive properties that characterize high grade gliomas. ${ }^{7-13}$ The infiltrative nature of high grade gliomas is responsible for much of the morbidity and mortality associated with these tumours. ${ }^{14}$ Surgical debulking of the tumour often constitutes only a tempo- rizing measure, as microscopic infiltrated foci of tumour will lead to eventual recurrence, often in areas that are surgically inaccessible. As a result, patients afflicted with high grade gliomas are faced with a poor prognosis, with less than $10 \%$ of patients surviving beyond 2 years. ${ }^{15}$ Such grim statistics emphasize the need to better understand the mechanisms that underlie glioma invasion, as these may lead to the identification of novel targets in the therapy of high grade gliomas.

While the expression of proteases constitutes only one aspect of glioma biology, several features of proteases make them an attractive focus for continued research, especially with respect to potential therapeutics. First, while high grade glioma cells often

From the Brain Tumour Research Group, Department of Neurology \& Neurosurgery, Montreal Neurological Institute, McGill University, Montreal.

RECEIVED JUNE 7, 1996. ACCEPTED IN FINAL FORM AUGUST 1, 1996.

Presented, in part, as the André Barbeau Memorial Prize paper at the Canadian Congress of Neurological Sciences, Victoria, British Columbia, June 23, 1995.

Reprint requests to: Dr. V.W. Yong, Departments of Oncology and Cllinical Neurosciences, University of Calgary, 3330 Hospital Drive N.W., Calgary, Alberta, Canada T2N 4N1 
have accumulated a variety of oncogenic mutations (gene amplifications, deletions, point mutations) of tumour suppressor genes, proto-oncogene-encoded growth factors, or growth factor receptors (e.g., epidermal growth factor receptor, EGFR) that collectively contribute to the malignant characteristics of the cell (reviewed in 16), these diverse cellular processes are "upstream" of protease function. Proteases may thus be attractive target molecules as they constitute the final effector molecules of invasion. Second, with the continuing rapid growth in the understanding of the regulation of protease activity, our means to manipulate the activity of proteases is increasing. In this regard, in vitro demonstrations have been extrapolated into in vivo trials with anti-matrix degrading metalloproteinase (MMP) agents in animal- and human-models of tumours. ${ }^{17-23}$ Third, the process of invasion is tightly linked with angiogenesis. Proteases which permit glioma infiltration may well be involved in the neovascularization process, ${ }^{5}$ such that effective anti-invasive agents may also be effective in the inhibition of angiogenesis. ${ }^{19}$ Finally, the observation that virtually all malignant tumours, both central and peripheral, utilize proteases to invade ${ }^{3.5 .24 .25}$ offers hope that a better understanding of proteases may have positive repercussions not only in the future therapy of gliomas, but also in the treatment of many other tumour-types.

The process of invasion thus consists of numerous events, beginning with aberrations in cell-surface growth factor receptors/ligands, second messenger systems within the cell, which culminate with the proteolytic effector limb of invasion. This article will present recent data that highlight each component of the invasion process.

\section{MetalloproteinaSES as EfFEctors of Glioma InVASion}

Proteases can be categorized into three broad classes according to the distinctive biochemistry of their active sites. Matrixmetalloproteinases (MMPs) require the binding of the zinc ion at the active site, hence the "metallo-" prefix. Serine- and cysteine-proteases are characterized by the amino acids that are critical to the catalytic function. As Table 1 illustrates, the majority of investigations correlating glioma invasiveness with proteolytic activity have focused on the MMPs as the predominant mediator of glioma invasion, although the serine-11.26,27 and cysteine-proteases ${ }^{28,29}$ have also been implicated.

Metalloproteinases represent a large family of zinc-dependent proteases that are capable of degrading almost all extracellular matrix macromolecules. ${ }^{5,30}$ To date, at least 10 subtypes have been identified, each distinguished by its molecular weight, substrate diversity, and regulation of expression. ${ }^{5,30}$ Their capacity to degrade a large variety of extracellular matrix (ECM) substrates (Table 1) is exploited by both physiologic- and pathologic-processes (Table 2). The importance of MMPs in normal physiology is most evident in processes that require the degradation and resorption of cellular and proteinaceous material. During wound healing, the digestion of damaged ECM and stroma by fibroblast-derived MMPs is prerequisite to the deposition of new ECM. ${ }^{31}$ As another example, the coordinated breakdown of bone matrix that occurs in bone growth and remodelling also requires the activity of MMPs. ${ }^{32}$ The physiologic roles of MMPs are an important consideration when contemplating these enzymes as targets of anti-invasive therapies.
Table 1: Matrix-Degrading Proteases Implicated in Glioma Invasion.

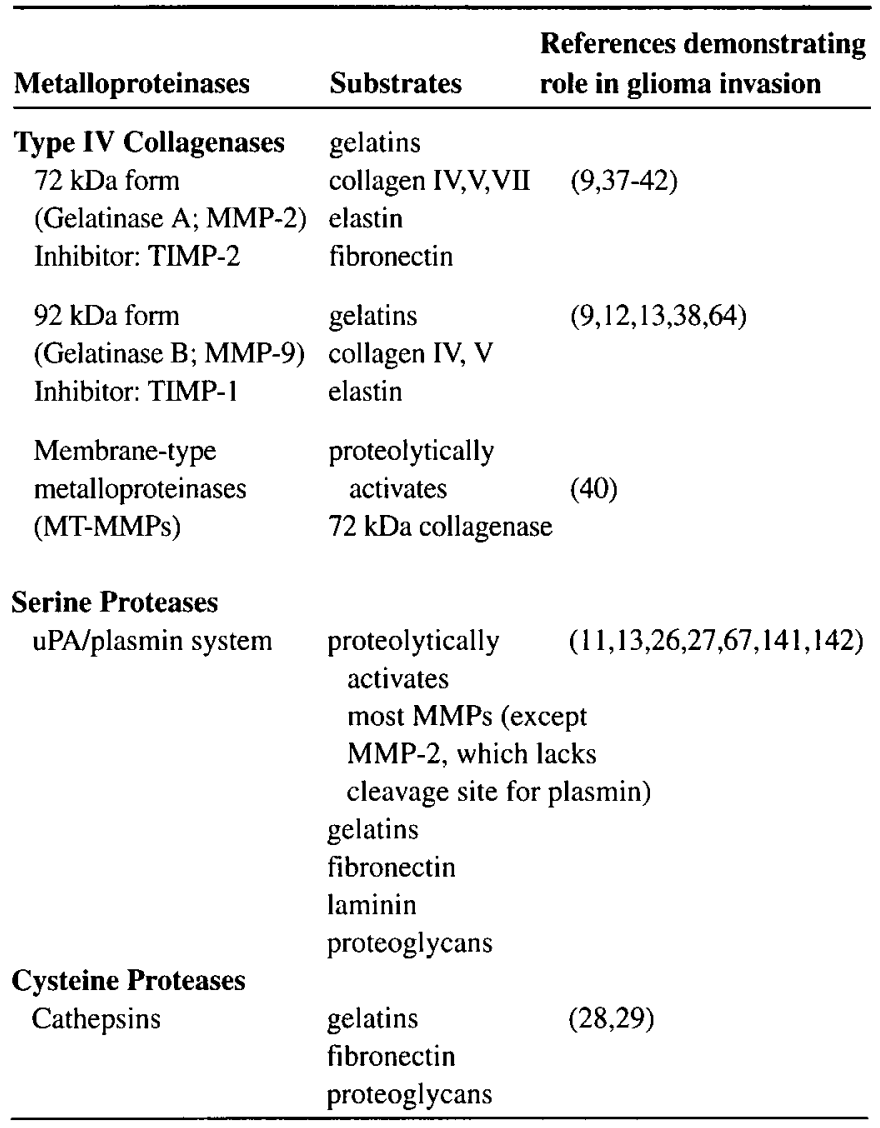

Table 2: Physiologic and Pathologic Roles of Metalloproteinases in Tissue Resorption/Degradation.

\begin{tabular}{ll}
\hline Normal processes & Pathologic Processes \\
\hline Ovulation & Cancer invasion \\
Blastocyst implantation & Tumour metastasis \\
Embryogenesis & Rheumatoid arthritis \\
Mammary development & Periodontal disease \\
Fetal membrane rupture & Wound healing \\
Bone growth/remodelling & Gastric ulcer \\
Angiogenesis & Angiogenesis \\
Macrophage function & \\
Neutrophil function & \\
\hline
\end{tabular}

(Reproduced with permission. Modified from Woessner, J.F. ${ }^{143}$ )

The elevated expression of MMP activity in tumours was first described by Liotta and colleagues ${ }^{33}$ in the context of B 16 melanoma cells, which demonstrated more type IV collagenase activity than their non-metastatic counterparts. Since then, MMP activity has been correlated with the invasiveness of many other tumours, ${ }^{4,5,24,34-36}$ strengthening the role of MMPs in tumour progression.

In tumours of the nervous system, immunohistochemical localization studies have confirmed that high grade human gliomas [glioblastoma multiforme (GBM) and anaplastic astrocytoma] express MMPs, whereas non-invasive low-grade astrocytomas and normal brain tissue do not. ${ }^{9}$ Additional evidence implicating MMPs in the invasive process of high grade gliomas is extensive, both in vitro ${ }^{8,12,13,37-41}$ as well as in vivo. ${ }^{40,42}$ 


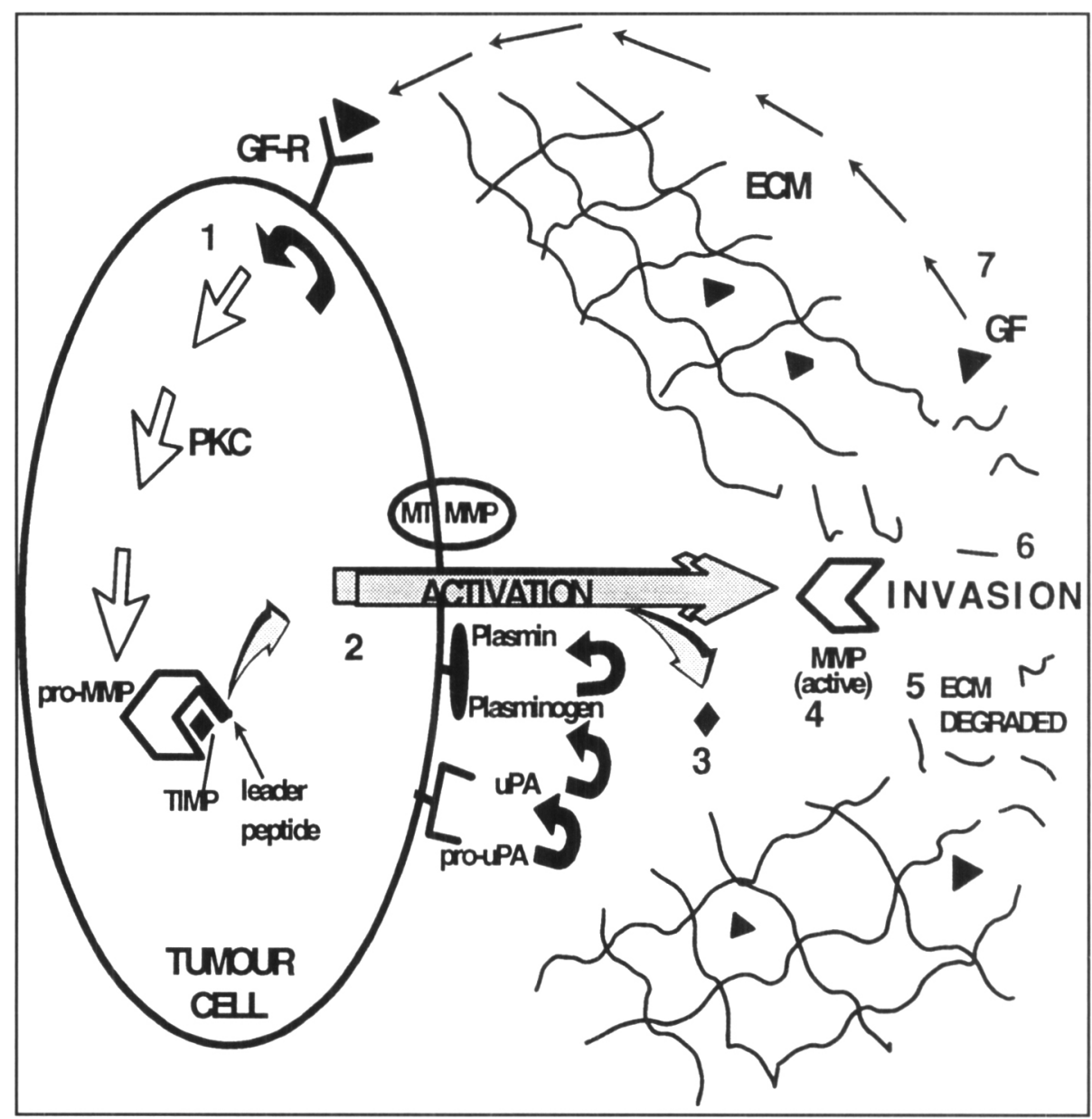

Figure 1: The Proteolytic Cascade of an Invading Tumour. (1) Aberrations in cell-surface signaling by growth factors and second messenger systems have been shown to enhance the expression of various proteases. MMPs are synthesized in their latent or inactive "pro" forms. (2) One of the steps in the activation of the secreted "pro"-MMP requires proteolytic cleavage of the signal peptide, which is mediated by serine proteases (the urokinase/plasminogen/plasmin system) and by non-secreted MMPs that reside within the cell membrane (MT-MMP; transmembranous MMP). The cell-surface receptors for components of the plasminogen cascade combined with the membranous localization of the MT-MMPs effectively concentrate this proteolytic activation of secreted MMPs close to the cell surface. Of note, the $72 \mathrm{kDa}$ type IV collagenase (MMP-2). which is suggested to be the predominant protease mediating glioma invasion, is not a substrate for cleavage by plasmin; rather, it is proteolytically activated by MTMMPs. Despite cleavage of the signal peptide, secreted MMPs remain inactive until they are dissociated from TIMPs (tissue-derived inhibitors of metalloproteinases; binds to active site of MMP). Following dissociation of the TIMP (3), MMP is fully active (4), leading to degradation of ECM barriers (5) and thereby permitting invasion (6). The breakdown of ECM may liberate growth factors from the matrix which acts to perpetuate the cycle (7).

Among the many members of the MMP family of proteases that have been identified in gliomas, the emerging data suggest that $72 \mathrm{kDa}$ - and the $92 \mathrm{kDa}$-type IV collagenases (MMP-2 and MMP-9, respectively) are primarily responsible for the invasive properties of high grade gliomas.

Comparing between MMP-2 and MMP-9, the former appears to predominate as the principal mediator of glioma invasiveness. In this regard, we have recently reported that the in vitro invasiveness of five different human glioma cell lines correlated closely $\left(r^{2}=0.95\right)$ with the level of MMP-2 activity detected in culture supernatants (Figure 2). The role of MMPs was further corroborated by the observation that pharmacologic inhibitors of MMPs resulted in a $>90 \%$ reduction in glioma invasion; conversely, increasing MMP-2 activity in non-transformed astrocytes resulted in an increase in their invasiveness. ${ }^{39} \mathrm{~A}$ similar correlation between invasion and MMP-2 activity in vitro was reported by Abe et al. in their survey of nine human glioma cell lines. ${ }^{37}$ As well, Sawaya et al. have recently reported a correlation between MMP-2 expression in vivo and increasing grade of the resected human glioma specimens, in which the MMP-2 activity of glioblastoma was five-fold greater than that of normal brain or low-grade glioma. ${ }^{42}$ Furthermore, studies in situ demonstrate relatively intense immunoreactivity for MMP-2 in high grade gliomas in contrast to virtual absence of labelling in the brain tissue surrounding the tumour mass. ${ }^{9,42}$

MMP-9 expression has also been demonstrated in vitro and in vivo in gliomas, but the relationship between invasiveness and MMP-9 expression has tended to be not as conclusive compared to that observed for MMP-2. ${ }^{12.13,38,41}$ Antibodies directed to either MMP-9 or its activator (urokinase/plasminogen) led to a reduction in glioma invasion by approximately $70 \% .{ }^{13}$ Similarly, in vivo, the level of MMP-9 activity derived from homogenates of surgical specimens was proportional to the grade of the 


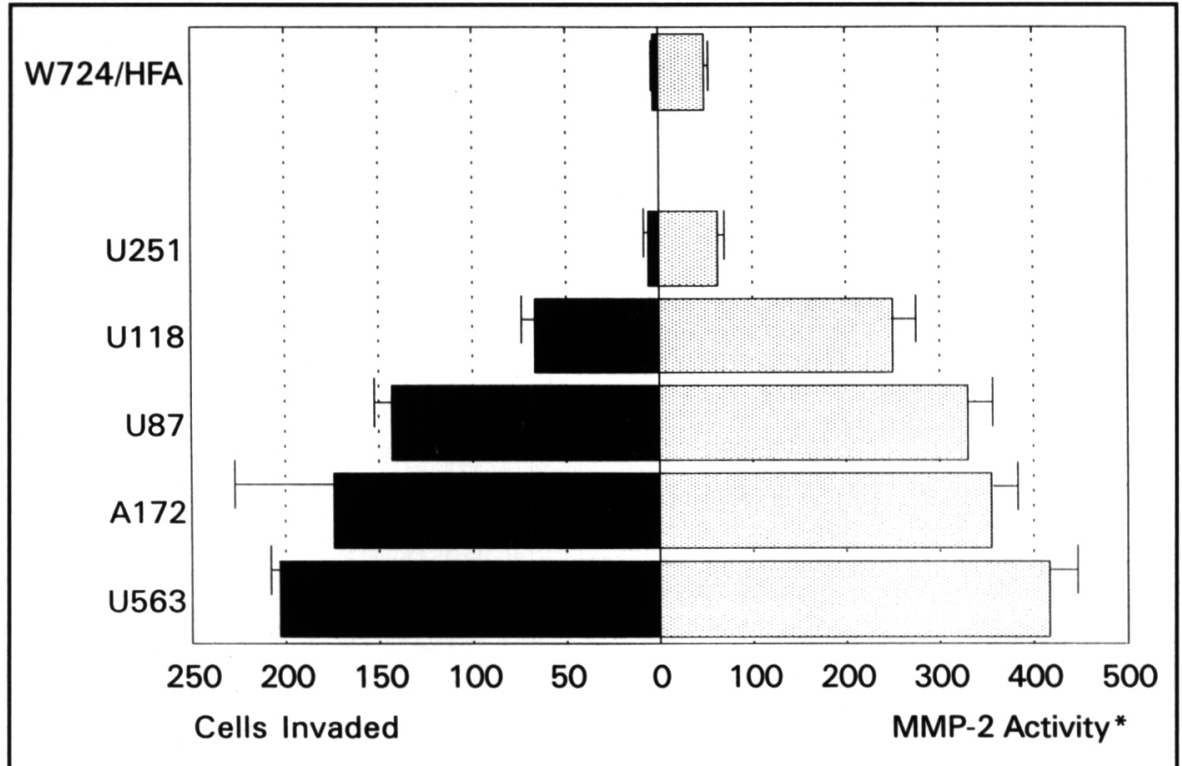

Figure 2: MMP-2 activity correlates with the invasiveness of human gliomas in vitro. A high degree of correlation $\left(r^{2}=0.95, p<0.01\right)$ was demonstrated between glioma invasiveness and the activity of MMP-2. In contrast to the four human glioma cell lines tested (U251, UII8, U87, A172, U563), non-transformed astrocytes (W724/HFA) exhibited virtually no invasiveness, which paralleled its low MMP-2 activity. Invasiveness was assessed in an in vitro invasion assay. MMP activities were assayed using a gelatin zymography. (Reproduced with permission. Modified from Uhm et al. ${ }^{39}$ )

glioma. ${ }^{12}$ However, the MMP-9 activity observed in the higher grade gliomas may have been, in part, attributable to endothelial cells present within the tumour bulk. This is supported by the observation that within a glioma mass, the MMP-9 immunoreactivity is intense in the endothelial cells of the vasculature in contrast to the relatively weaker labelling of the tumour cells themselves. ${ }^{9}$ This observed high MMP-9 activity of homogenized high grade tumours may be related to the increased presence of endothelial cells, thus reflecting the degree of angiogenesis.

As MMPs are synthesized as inactive, pro-enzyme forms, activation of both MMP-2 and MMP-9 requires the proteolytic cleavage of a leader peptide, reminiscent of the proteolytic cascade that activates pro-enzymes of the pancreas and coagulation factors. Proteolytic activation of most MMPs, including MMP9 , is mediated by the urokinase/plasminogen/plasmin system, members of the serine-protease family. ${ }^{5,30}$ In contrast, proMMP-2 has no apparent plasmin-susceptible propeptide cleavage site (Table 3) and thus requires a different protease for activation. Recent reports have confirmed that pro-MMP-2 activation is mediated by the membrane-type MMPs (MTMMPs) ${ }^{25,34,43-46}$ (Table 3, Figure 1). Therefore, as glioma invasiveness correlates with MMP-2 activity, invasion would be predicted to also be dependent on the activity of the activating enzyme, membrane-type metalloproteinase (MT-MMP). In this regard, Rao's group has recently reported the MT-MMP-mediated activation of pro-MMP-2 in high grade gliomas. ${ }^{40}$ Taken together, the emerging literature suggests that glioma invasion utilizes numerous proteases, of which the predominant one may be MMP-2, and that the membranous localization of the activating MT-MMP effectively permits the concentration of proteolytic activity close to the cell surface at the advancing tumour margin.

Table 3: Type IV Collagenases Demonstrated in Glioma Invasiveness.

\begin{tabular}{lll}
\hline & $\mathbf{7 2}$ kDa (MMP-2) & 92 kDa (MMP-9) \\
\hline Role in glioma & yes & yes
\end{tabular}

invasion

Genetics ${ }^{1}$

promoter lacks AP-1; characteristic of constitutively expressed or "housekeeping" gene

Activation by: plasmin

other modes of activation

Inhibition by TIMP $^{2}$

Expression by glioma and/or endothelial cells ${ }^{3}$

Possible relative role Invasion $>$ Angiogenesis in invasion vs. angiogenesis

${ }^{1}$ AP-1 sequence. Binding of Fos/Jun dimer transcription factor to the AP-1 sequence within the promoter of a gene may induce transcription of that gene. Genes whose promoter regions lack the AP-1 sequence are thus not amenable to Fos/Jun-mediated transcriptional activation. AP-1 sequence (phorbol ester responsive element) is present in the promoter of MMP-1, MMP-3, MMP-9. The promoter for MMP-2 lacks AP-1.

${ }^{2}$ TIMP; tissue-derived inhibitor of metalloprotease. Both TIMP-1 and TIMP-2 are capable of binding to either MMP; the table notes the predominant TIMP - MMP interaction.

${ }^{3}$ Expression as assessed by immunoreactivity of tumour specimen in situ (9) MMP; matrix degrading metalloproteinase. 
In summary, while the expression of numerous MMPs has been documented in gliomas, MMP-2 and possibly MMP-9 appear to be the principal MMPs that mediate the invasive phenotype. As the activity of these enzymes requires selective proteolysis of the leader peptide, the importance of MMP-activators must be underscored.

\section{Regulation of Glioma Protease Expression}

As evidence implicating the role of MMPs in glioma invasiveness accumulates, so too is the data regarding their regulation. Like other enzymatic systems, there are multiple regulatory pathways that modulate MMP expression, for if left unchecked, the powerful degradative activities of these enzymes may lead to extensive tissue damage and destruction. Regulation of MMP expression occurs at three levels: 1) gene transcription, 2) proenzyme activation by selective proteolysis; and 3 ) inhibition by tissue-derived inhibitors of metalloprotease (TIMPs) (Figure 1). These modes of MMP regulation offer not only a better understanding of MMP function, but also reveal areas of MMP expression that may be amenable to potential anti-invasive therapeutics.

\section{Genetic regulation of MMP expression}

The expression pattern of MMPs with respect to specific growth factors, cytokines, and tumour promoters suggests a convergence of control mechanisms on the transcription of MMP genes. ${ }^{30,47}$ While the expression profile is complex, an analysis of the promoter sequence of several MMP genes has shed light on the possible molecular basis for the similarities and differences observed in the expression patterns of the different MMP family members.

In response to stimulation by a growth factor, the cell must be able to selectively turn on specific genes whose coordinate expression will lead to the intended effect of the growth factor. Genes that will be targeted for induction are identified by unique DNA sequences within their promoter regions that bind specific transcription factors that mediate gene induction. Transcription factors that are frequently expressed in response to various growth factors include $c$-fos and $c$-jun, whose protein products form the Jun/Fos dimer, a transcription factor that binds to and consequently activates genes whose promoter regions contain the sequence referred to as AP-1 (also known as phorbol ester responsive element).

Genes that contain the AP- 1 sequence within their promoters can be selected for induction via the Jun/Fos transcription factor (Figure 3). Thus, sequences such as AP-1 confer a "tag" which identifies select genes for coordinate induction in response to specific stimuli to the cell. This may explain how certain MMPs are induced simultaneously in response to stimulation by a growth factor or oncogene ${ }^{30,47,48}$ For example, in epidermal growth factor (EGF)-stimulated fibroblasts, the increase in Fos/Jun transcription factor leads to the co-induction of both MMP-1 and MMP-3, both of which contain the AP-1 sequence targeted by Fos/Jun. Another promoter sequence element that acts to identify specific genes for induction is the PEA3 sequence, which binds the transcription factor encoded by the cets oncogene.$^{49}$ PEA 3 may likely work in conjunction with AP-1 to modulate the induction of genes that contain these promoter sequences. The coordinate gene-regulation model may be some- what simplistic, as there are examples in which one of these genes may be selectively stimulated without an effect on the other. In general, however, the AP-1 and PEA3 regulatory elements seem to constitute important components in the transcriptional control of MMP genes.

In contrast, sequences such as TATA and GC-rich boxes that are more widespread in their distribution among genes do not confer inducibility to that gene. Rather, genes with only these sequences in the promoter tend to be constitutively expressed and are therefore often referred to as "housekeeping" genes. In this regard, unlike the other MMPs, the gene for MMP-2 lacks any sequence element that would confer inducibility (Figure 3), which may explain the observation that MMP- 2 mRNA levels tend not to fluctuate. As such, the regulation of MMP-2 expression both physiologically and in pathologic states such as cancer likely requires post-transcriptional and post-translational modifications in response to cell-surface stimuli and intracellular second messenger systems (Figure 1).

\section{MMP regulation: growth factors}

Cellular growth is a key point of convergence for many regulatory pathways, in which a critical balance is achieved between growth promotion and differentiation. There is extensive evidence in peripheral tumours as well as in gliomas demonstrating the step-wise accumulation of mutations in genes that encode growth factors and growth factor receptors (oncogenes) as well as in genes that physiologically act to restrain growth (tumour suppressor genes). These mutations eventually tip the balance in favour of growth promotion, leading to uncontrolled growth and ultimately, to the malignant phenotype. ${ }^{16,50-53}$

A large proportion of mutations observed in high grade gliomas have been demonstrated in genes that encode growth factors and their respective receptors, which are frequently tyrosine kinases (reviewed in 16). Mutations have been reported for the following: epidermal growth factor (EGF) and its receptor (EGFR), basic fibroblast growth factor (bFGF) and its receptor (bFGFR), insulin-like growth factor (IGF-1) and its receptor (IGF-1R), platelet derived growth factor (PDGF) and the transforming growth factor-beta (TGF- $\beta$ ) family of proteins. The concurrent synthesis of ligand and receptor within a tumour cell may thus lead to an autocrine stimulation of the tumour.

While over-activity of these cell-surface signaling systems has been shown to enhance both the proliferative and invasive aspects of the glioma phenotype, much of the research into growth factor systems remains focused on the proliferative consequences of the mutations. However, data addressing the link between growth factors and invasion is emerging.

Numerous reports have demonstrated the effect of various growth factors/receptors on the invasiveness of gliomas. Of the many cell-signalling systems known to be aberrant in glioblastomas, the EGFR gene has been an area of extensive research. Located at 7p11-p12, it is the most commonly amplified gene in glioblastomas. The frequency of amplification appears to correlate with increasing tumour grade, being present in $3 \%$ of astrocytomas, $7 \%$ of anaplastic astrocytomas, and nearly $40 \%$ of glioblastomas. ${ }^{51}$ Several reports have addressed the role of EGFR signal transduction system in glioma invasion. Using a xenograft model, in which spheroids of human glioma cells are juxtaposed to rat brain aggregates, exogenously applied EGF led to an increase in the invasion of tumour cells into the target cell 


\section{Comparison of Upstream Promoter Sequences of MMP Genes}

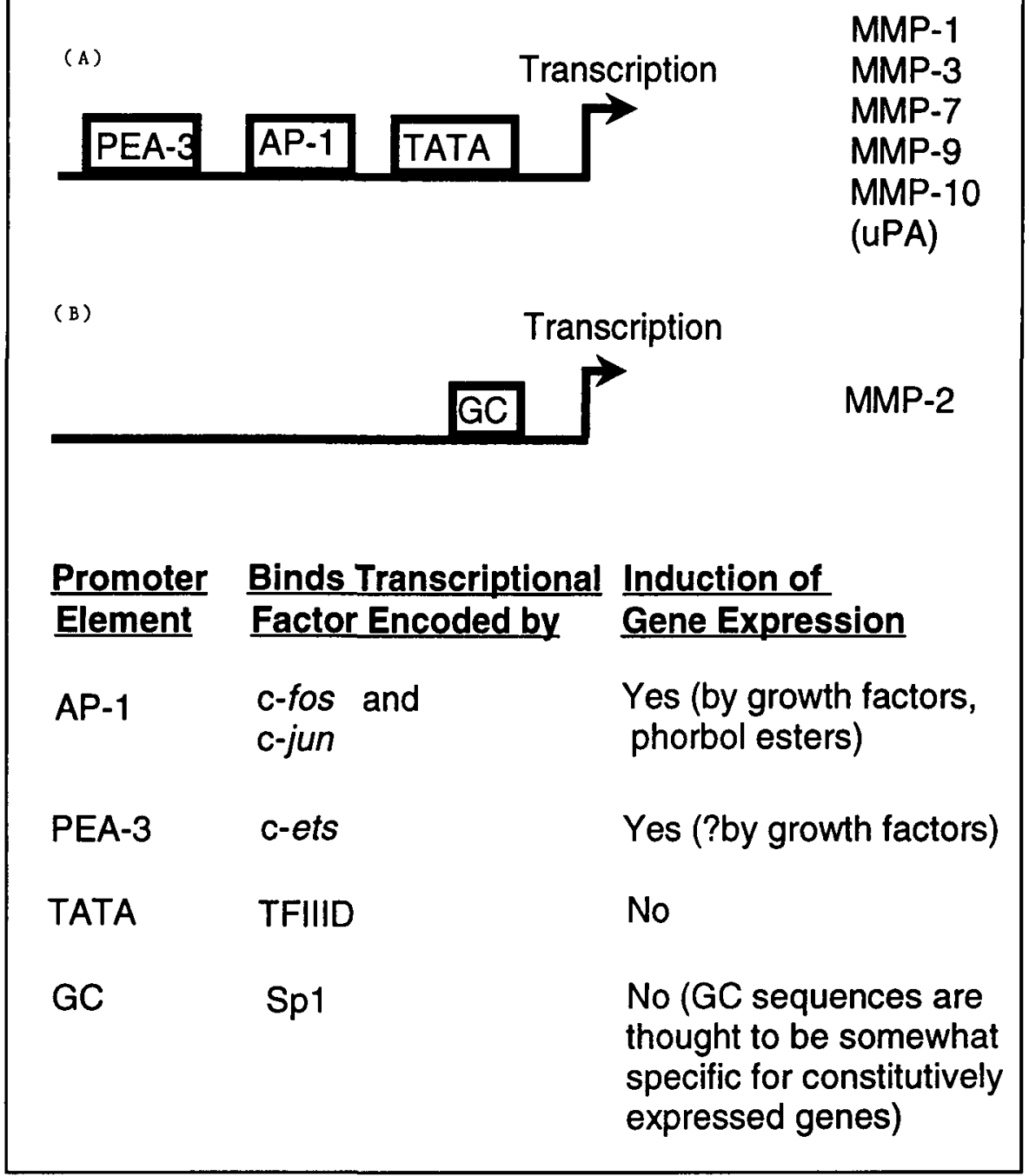

Figure 3: Comparison of the upstream promoter sequences of MMP genes. Unlike the promoter described in (A), the promoter in $(\boldsymbol{B})$ associated with $M M P-2$ contains no DNA sequences that bind factors that induce gene expression. The relative lack of induction sequences on MMP-2 promoter is characteristic of "housekeeping" genes (e.g., widespread, constitutive expression). This is in contrast to the (A) promoters, which bear AP-I and/or PEA3 sequences. A cell surface signal, such as growth factor stimulation, may lead to induction of c-jun and c-fos oncogenes. The Jun/Fos dimers can bind to the AP-1 site, thereby inducing expression of AP-1 bearing genes. This may be one way by which promoter elements may allow coordinate regulation of numerous genes. Example: co-induction of MMP-3 with its activator, $u P A{ }^{30}$ The following genes contain the PEA3 element: MMP-1, MMP-3, MMP-7, MMP-10. (Reproduced with permission. Modified from Matrisian, L.M. ${ }^{47}$ )

mass. ${ }^{54.55}$ The stimulatory effect on invasion was selective, as EGF, at the dose employed, did not enhance proliferation. ${ }^{54}$ In similar studies in which several growth factors were surveyed, EGF constituted the most potent agent to stimulate invasion into the brain aggregates. ${ }^{56,57}$ The apparent destruction within the target cell mass was interpreted to be an indication of the invasion process rather than simply migration alone. However, while it is likely that the invasion and tissue destruction were mediated by proteases, MMPs or other protease levels were not assayed in these studies.

While the mechanism of EGF-mediated invasion remains unclear in gliomas, specifically with respect to the possibility of involvement of proteases, there is evidence in other experimental models that links the EGF/EGFR signal transduction to the expression of proteases. Hu et al. ${ }^{48}$ investigated the effect of EGF in 3 T3 fibroblast cells, in which EGF led to induction of expression of fos and jun oncogenes as well as MMP-I and MMP-3. As both MMP-1 and MMP-3 promoters contain the AP-1 site, ${ }^{30,47}$ they studied the effect of EGF stimulation in 3T3 cells that genetically lack the fos and jun genes. In the cells mutant for both fos and jun, EGF could no longer induce MMP1/MMP-3 expression, demonstrating that the fos/jun-encoded transcription factors, when present, transduce the cell-surface EGF signal to the level MMP genes. Similarly, PDGF-induced expression MMP-1 and MMP-3 was also shown to be jun/fos 
dependent. While it remains unclear if the EGF/EGFR or other growth factor/receptor systems induce MMPs by the jun/fos mediators in gliomas, it is an attractive hypothesis to consider with respect to the mechanism of coordinating, at the genetic level, the expression of proteases in malignant cells.

Another growth factor implicated in glioma invasiveness is basic fibroblast growth factor (bFGF), an angiogenic factor and mitogen that is expressed in increased amounts by astrocytic tumours. ${ }^{58-60}$ Since the tumours have also been shown to express the bFGF receptors, ${ }^{61,62}$ there is again the potential for an autocrine loop. In vitro, bFGF has been shown to increase glioma motility ${ }^{63}$ as well as invasion via an increase in the activity of MMP-9. ${ }^{64}$ The molecular mechanism responsible for the increased MMP-9 activity may be three-fold. First, bFGF stimulation may induce the transcription of the MMP-9 gene, whose expression is increased in glioblastomas. ${ }^{12,13}$ bFGF signal is, in part, transduced downstream by the expression of c-fos and cjun oncogenes. Therefore, the bFGF/bFGFR autocrine stimulation may induce transcription of MMP-9 via the AP-1 site present in the MMP-9 promoter (see Figure 3). Second, the uPA gene, which encodes part of the serine protease cascade that activates pro-MMP-9, also possesses the AP-1 promoter sequence, ${ }^{65}$ which may explain the potent stimulation of MMP-9 expression by $\mathrm{bFGF}^{66}$ that is accompanied by an elevation of uPA in glioblastomas both in vitro ${ }^{13}$ and in vivo. ${ }^{26,67}$ Thus, the coordinate induction of MMP-9 with its proteolytic activator (UPA) may synergize to augment MMP-9 activity.

In addition to EGF and bFGF, other growth factors such as PDGF, TGF, and various cytokines also appear to employ transcription factors and specific promoter elements to effect induction of MMP expression at the level of transcription. However, as the MMP-2 gene lacks the promoter elements that facilitate gene induction (Figure 3), mechanisms other than transcriptional up-regulation must underlie the augmented MMP-2 activity demonstrated in many cancers, $, 5,68,69$ including glioblastomas. ${ }^{26,37,39,42}$ In this regard, there is an example of regulation of MMP-2 expression at post-transcriptional level in human fibroblasts, in which the increased expression of MMP-2 in response to growth factor stimulation is mediated by an increase in the stability of its MMP-2 mRNA. ${ }^{70}$ However, whether such post-transcriptional regulation of MMP-2 expression occurs in gliomas has not yet been addressed. In contrast, there is extensive evidence demonstrating numerous post-translational modifications in MMP-2 expression.

\section{MMP Regulation: Post-translational mechanisms of activa- tion and inhibition}

Figure 1 outlines the various activation/inhibition pathways that act on the MMP enzyme. As MMPs, like many other proteases, are initially synthesized in their inactive, pro-enzyme form, the primary mode of activation requires the proteolytic cleavage of the leader peptide (Step 2 of Figure1). The proteolytic processing of most MMPs is mediated by the serine protease system of uPA/plasminogen/plasmin. However, as the leader peptide of pro-MMP-2 lacks a cleavage site for plasmin, the search for another form of activating protease to process MMP-2 had been an intense area of research. It was known that cell membrane contained the proteolytic activity necessary for the processing of pro-MMP- $2,{ }^{30}$ but it was not until recently that this activating protease was identified as an integral plasma membrane protein, the first membrane-type MMP (MT-MMP-1) to be discovered. ${ }^{34}$ Shortly after, a second MT-MMP (MTMMP-2) was identified by the same group of investigators. ${ }^{43}$ The membranous localization of the MT-MMPs effectively concentrates the proteolytic activation of MMP-2 in the vicinity of the cell surface to facilitate the process of invasion at the advancing tumour margin.

MT-MMP-mediated activation of MMP-2 has been demonstrated in numerous malignancies (reviewed in 71), including those of lung, ${ }^{72}$ gastric, ${ }^{73}$ and breas ${ }^{44}$ origin. Furthermore, Yamamoto et al. have recently reported the correlation between MT-MMP-mediated activation of MMP-2 and the invasiveness of human glioblastomas in vivo. ${ }^{40}$ In addition to their key role in mediating tumour invasion, MMP-2 and its activator, MT-MMP, may further complement the process of tumourigenesis by facilitating angiogenesis, as MT-MMP-mediated activation of MMP-2 has also been characterized in endothelial cells. ${ }^{45,74}$ Interestingly, in the brain, MT-MMP expression has recently been found to be predominantly concentrated in the white matter microglia. ${ }^{75}$ We postulate that this may, in part, underlie the reason why gliomas tend to infiltrate through white matter tracts; MT-MMPs expressed by the microglia may contribute to the proteolytic activation of glioma-derived pro-MMP-2 molecules, thereby serving as a substrate permissive to infiltration.

In addition to the secretion of MMPs and their subsequent activation, cells simultaneously produce inhibitors (TIMPs; tissue-derived inhibitors of metalloproteinases), which can bind to the MMPs and inactivate their proteolytic function. ${ }^{70.76-79}$ Therefore, the net proteolytic, and thus invasive, potential of a tumour in part reflects a balance between the two opposing mechanisms. While TIMP-1 and TIMP-2 bear approximately $40 \%$ sequence homology and are capable of binding to all forms of MMPs, ${ }^{79,80}$ they do display a degree of selectivity (Table 3), with TIMP-1 being more specific for MMP-9 while TIMP-2 acts more selectively on MMP- $2 .{ }^{79,81}$

As inhibitors of MMPs, the prediction would be that increases in TIMP levels would be associated with a decrease in invasiveness. In keeping with this prediction, the anti-invasive effects of TIMPs have been demonstrated in numerous malignancies in vitro (reviewed in 82), including gliomas. ${ }^{41,83,84}$ The in vivo efficacy of TIMPs have been reported by DeClerck et al., in which the down-regulation of MMP activity in tumours transfected with TIMP-2 greatly diminished local invasion as well as partially suppressing hematogenous metastasis in nude mice. ${ }^{85}$ In gliomas, overexpression of TIMP-1 into an invasive glioma cell line (low TIMP levels prior to transfection) decreased the in vitro invasiveness by $>60 \%{ }^{83}$ Similarly, in vivo, TIMP levels were lowest for glioblastomas in contrast to lower grade gliomas or normal brain, which had relatively higher TIMP levels. ${ }^{86}$ Immunohistochemical data support this, in that glioblastomas demonstrated relatively weaker labelling for TIMP-1 compared to the stronger labelling observed in non-infiltrative tumours, such as meningiomas and neurinomas. ${ }^{9}$

However, high TIMP levels are not always associated with inhibition of invasiveness. In a survey of nine glioma cell lines, the most invasive cell line demonstrated a high MMP:TIMP ratio and the least invasive line exhibited the lowest MMP:TIMP ratio; however, for the remaining seven cell lines, the MMP:TIMP ratio did not correlate with invasiveness. ${ }^{41}$ Furthermore, in a study of non-Hodgkin's lymphomas, high 
TIMP-1 levels surprisingly correlated with the more aggressive phenotype ${ }^{87.88}$ Similarly, enhanced stromal expression of TIMP2 in breast carcinomas correlated with tumour recurrence. ${ }^{89}$ In this regard, there is recent evidence that TIMP-2 may actually participate in the activation of MMP-2, in which the proteolytic activation of MMP-2 by the membrane-type MMP (MT-MMP) requires TIMP-2 as a "cofactor" necessary for the activation process. ${ }^{46}$ In this model, MT-MMP must first bind TIMP-2, following which the MT-MMP:TIMP-2 complex is then able to bind the pro-MMP-2 on the cell surface where the activation will take place. The dual role of TIMP-2 in both the activation and inhibition of MMP activity may be concentration-dependent, in which low-to-moderate levels of TIMP-2 may facilitate MMP-2 activation, whereas higher TIMP-2 levels lead to inhibition of MMP activity. This may, in part, explain the observation that in order to cause protease inhibition, the stoichiometry between a TIMP and its respective MMP is higher for the TIMP-2:MMP-2 pair (stoichiometry of $2: 1$ ) $^{90}$ compared to the 1:1 stoichiometry required for TIMP-1:MMP-9. ${ }^{82}$

TIMPs have also been reported to exhibit growth-promoting effects in a wide variety of cells. ${ }^{91-97}$ These multiple and apparent dichotomous effects of TIMPs may be a consequence of the multiple-domain structure of these molecule. ${ }^{82}$ While one domain of a TIMP molecule may mediate the interaction with its respective MMP to cause protease inhibition, other TIMP domains, likely acting through receptors on the cell surface, may mediate the non-inhibitory effects of TIMPs. ${ }^{93}$

While the experimental support for the premise that a high MMP:TIMP ratio correlates with invasiveness is not absolute, high MMP activities are generally associated with tumour invasiveness. As such, reciprocal regulation of MMP and TIMP (increase MMP, decrease TIMP) should achieve a greater degradative activity than that obtained by increases in MMP expression alone. Examples for this kind of reciprocal regulation are rare. In models of bone resorption, Concanavalin $A$ or retinoic acid can induce MMP-2 while TIMP is downregulated, leading to a highly degradative state. ${ }^{98}$ Whether reciprocal regulation of MMP and TIMP occurs in gliomas remains to be determined. For the most part, growth factors and oncogenes that induce MMP expression tend to coordinately induce the corresponding TIMP, likely due to the fact that the TIMP promoter contains the AP-1 element which is also present in many MMP genes as well (except MMP-2). How co-induction of a MMP species with its inhibitor translates into increased invasiveness remains speculative, with the possibility that the co-induction is not equal but rather balanced in favour of the MMP.

In summary, the net proteolytic, and thus invasive, potential of a given tumour cell may be dependent on the interplay of at multiple enzymatic processes. While the principal effector of glioma invasion may be MMP-2 activity, this activity is dependent upon its activation by MT-MMPs which is counterbalanced by the inhibitory effects of TIMP.

\section{MMP regulation: potential role for protein kinase $\mathbf{C}$ (PKC)}

Protein kinase $\mathrm{C}(\mathrm{PKC})$ is a phospholipid-dependent serinethreonine kinase that functions as an intermediary in the transduction of signals from the cell-surface to the level of the nucleus. ${ }^{99}$ Various growth factor signals, in part, funnel through PKC; these include PDGF, EGF, and IGF. As a convergence point for growth factor signals, abnormalities in PKC activity have been found to contribute to the tumourigenesis of a wide variety of neoplasms. ${ }^{100}$ In this regard, we have previously reported that high grade gliomas are characterized by high levels of PKC activity and that inhibition of this second messenger system can dramatically reduce glioma growth in vitro. ${ }^{101-106}$ Furthermore, growth of malignant gliomas in vivo have also been shown to be decreased by antisense oligonucleotides directed against PKC. ${ }^{107,108}$

Based on these previous results and the observations implicating $\mathrm{PKC}$ in the invasiveness of a variety of peripheral tumours, ${ }^{100,109-113}$ we decided to investigate the possibility that the abnormally high PKC activity in high grade gliomas contributes to the invasive characteristics of these cerebral malignancies. In a recent report, we demonstrated that the invasiveness of human glioma cells in vitro correlates with the activity of MMP-2, which in turn, may be regulated by signal transduction through $\mathrm{PKC} .{ }^{39}$ In this regard, the treatment of highly invasive glioma cells with calphostin $\mathrm{C}$, a selective inhibitor of PKC, led to a decrease in the MMP-2 activity with a concomitant reduction in glioma invasiveness. Conversely, nontransformed human astrocytes, which are poorly invasive, could be stimulated by a phorbol ester (activator of PKC) to significantly increase their MMP-2 activity and their degree of invasiveness.

The mechanism by which PKC modulates MMP-2 activity and invasiveness of gliomas is not yet clear. While PKC activity leads to the formation of the Jun/Fos transcription factor, ${ }^{1 / 4}$ MMP-2 cannot be induced in this manner, as its gene lacks the promoter sequence elements (AP-1) required for induction by Jun/Fos (see Figure 3). Therefore, PKC's regulation of MMP-2 activity is likely to be post-transcriptional and/or post-translational.

Based on our previous data, ${ }^{39}$ we hypothesize that the increased MMP-2 activity in human gliomas may be secondary to a PKC-mediated stimulation of the membrane-type MMP (MT-MMP), the enzyme which proteolytically activates MMP2. Data that suggest this postulate are four-fold. First, as we have reported, $\mathrm{PKC}$ activity in gliomas is abnormally high ${ }^{101-106}$ and selective $\mathrm{PKC}$ inhibitors can reduce invasion in parallel with a reduction in MMP-2 activity. ${ }^{39}$ Second, stimulators of PKC activity phorbol esters enhance MMP-2 activation in fibroblasts $^{115}$ and in astrocytes. ${ }^{39}$ Third, mRNA levels of MT-MMP increase in response to PKC agonists in breast carcinoma cells, ${ }^{44}$ fibrosarcoma cells, ${ }^{116}$ and in endothelial cells, ${ }^{45}$ which are accompanied by increased MMP-2 activation.

Preliminary data from our laboratory suggest that MT-MMP activity, and thus the proteolytic activation of MMP-2, may be under $\mathrm{PKC}$ control. Using reverse-transcription polymerase chain reaction (RT-PCR) techniques to analyze MT-MMP transcripts, we have demonstrated that calphostin $\mathrm{C}$ (PKC inhibitor) treatment leads to a $>50 \%$ decrease in the level of MT-MMP mRNA in glioblastoma cell lines (unpublished data). Given that calphostin $\mathrm{C}$ does not alter the level of MMP-2 transcripts (unpublished data), the observed decrease in MMP-2 activity following calphostin $\mathrm{C}$ treatment may, therefore, be a consequence of post-translational mechanisms, in which decrease in MT-MMP levels may lead to a decrease in the proteolytic activation of pro-MMP-2. Conversely, it would be of interest to determine if the observed increase in MMP-2 activity and invasiveness of non-transformed astrocytes upon treatment with phorbol ester (PKC activator) ${ }^{39}$ is a consequence of up-regulated 
MT-MMP transcription induced by PKC stimulation. These experiments, as well as investigations into identifying which PKC isoform(s) modulates MT-MMP transcription, are currently underway in our laboratory.

In addition to its effect on MT-MMP and MMP-2 activity, PKC may also influence the activity of other proteases as well. In non-neurologic tumours, PKC activity has been correlated with the expression of other metalloproteinases such as MMP-1 and MMP-3,117 MMP-9,118,119 and stromelysin-1.120 Furthermore, PKC activity also stimulates the expression of the serine-proteases (uPA/plasminogen/plasmin) that are required to proteolytically activate most MMPs. ${ }^{30.121}$ As well, cathepsin B, a cysteine protease, has also been shown to be induced by PKC activation. ${ }^{122}$ While presence of these proteases has been demonstrated in gliomas, ${ }^{28,29}$ the role of PKC in modulating their expression patterns is not known at this time.

PKC's strategic positioning in the signal transduction pathway renders this enzyme system a potentially important target for therapeutics of gliomas. As a mediator of signals from the cell surface, PKC plays a central role in transducing mitogenic signals induced by the multitude of growth factors and receptors that are frequently mutated in high grade gliomas. In addition to growth promotion, PKC can affect the activity of proteases, as antagonists of PKC result in a decrease in MMP-2 activity with a parallel reduction in glioma invasiveness. ${ }^{39}$ Furthermore, the role of PKC in the expression of MMPs in endothelial cells implicates PKC in the process of angiogenesis. ${ }^{123-127}$ High PKC activities in gliomas may also protect the tumour cell from undergoing programmed cell death (apoptosis), as the downregulation of PKC with pharmacologic inhibitors ${ }^{128,129}$ and isoformspecific antisense oligonucleotides ${ }^{130}$ can induce apoptosis of glioma cells in vitro. Thus, therapies that target PKC may have a global impact on numerous aspects of glioma biology, encompassing cell proliferation, invasiveness, as well as the neovascularization process that is required to permit tumour growth.

\section{Clinical Perspectives}

The invasive process is truly a cascade of events. The invading cell may ignite the chain of events by exploiting the autocrine stimulation derived from its mutated growth factor and receptor systems (Figure 1). These growth factors utilize the intracellular signaling pathways, such as PKC, to ultimately effect the induction of proteases capable of degrading the ECM. While some proteases function as activators, others, such as MMP-9 and MMP-2 may be directly responsible for the ECM proteolysis. Unlike most other MMPs, MMP-2 lacks the regulatory DNA sequences necessary for transcriptional induction by growth factors signals. Rather, MMP-2 is likely constitutively expressed as pro-enzyme that is proteolytically processed to its active state by MT-MMP, which by virtue of its membranous localization permits concentration of the enzyme activity at the cell surface. When the balance between activation and TIMPmediated inhibition favours proteolysis, ECM degradation ensues.

Each step in the chain of events represents a potential target for anti-invasive therapy. While genetically dominant mutations such as EGFR amplifications are not easily amenable to intervention, more downstream signal transduction pathways such as PKC may offer more hope for therapeutics, ${ }^{102,130-134}$ especially given PKC's apparent central positioning downstream from cellsurface signaling systems. Promising results in vitro ${ }^{135-137}$ have led to studies in patients using pharmacologic agents that demonstrate anti-PKC effects (Tamoxifen) which demonstrated clinical and radiological improvements, albeit in a limited subset of glioma patients. ${ }^{134.138}$ Furthermore, the use of antisense oligonucleotides that are complementary to the mRNAs encoding specific $\mathrm{PKC}$ isoforms have also demonstrated striking results against gliomas in animal models. ${ }^{107,108}$ Compared to pharmacologic inhibitors, antisense approach permits selective targeting of specific PKC isoforms, of which at least 10 have been identified to date. ${ }^{131}$ This is an important consideration with respect to potential toxicity in vivo, especially since various PKC isoform are expressed in many normal cells of the nervous system, including astrocytes, oligodendrocytes and neurons. As to which PKC isoform mediates MMP expression and invasiveness is not known; such information may be invaluable in the design of more selective antisense therapeutics.

As expression of ECM-degrading proteases constitute a characteristic that is virtually universal to all malignant tumours, the targeting of proteases makes intuitive sense with respect to antiinvasive therapy. Fortuitously, Nature has provided key clues in TIMPs, the natural inhibitors of matrix-metalloproteinases. The biochemistry and biophysics of the TIMP:MMP interaction have been the foundation for the strategies underlying the development of synthetic inhibitors of MMPs. ${ }^{82.85}$ An example of an agent that has generated a great deal of interest is BB-94 (batimastat), a broad spectrum MMP inhibitor whose mechanism of action is likely related to its high affinity binding via the hydroxamate group to the $\mathrm{Zn}^{++}$pocket of MMPs. ${ }^{23}$ Encouraging results demonstrating the efficacy of batimastat in reducing the invasiveness and metastasis of ovarian-, lung-, and colon-carcinomas in animal models ${ }^{22.23}$ have led to clinical trials in patients with malignant ascites. ${ }^{23,139}$ While a favourable response was observed in batimastat-treated patients, the poor oral bioavailability of batimastat may limit its use clinically. In this regard, a related MMP inhibitor, marimastat, may represent a major advance in the development of orally active compounds; preliminary results from a phase I healthy volunteer study showed that plasma levels of marimastat can reach levels $>250$ times the $\mathrm{IC}_{50}$ for MMP-2 inhibition. ${ }^{139}$

While these agents are in the early stages of development, the encouraging preclinical- and clinical data lend optimism to possibility that MMPs of gliomas as well as in other malignancies may be one day amenable to therapeutics. However, at least two issues illustrate possible sources of skepticism.

First, in addition to the pathologic functions mediated by MMPs, they are also critical to innumerable physiologic processes (Table 2), thereby raising justifiable concerns about potential toxicity and side effects. However, there is already strong precedence of successful targeting of MMPs in the treatment of hypertension, in which the inhibitors of angiotension converting enzyme (ACE), a metalloproteinase, are associated with minimal side effects. Furthermore, while the long term effects remain to be fully evaluated, broad-spectrum MMP inhibitors such as marimastat appear to be well tolerated in preliminary phase I/II studies.

Second, while the principal objective of anti-protease therapy has been to target tumour invasion, glioblastomas, like many malignancies, have already infiltrated surrounding structures by 
the time that they are detected, thereby potentially limiting the application of anti-invasive therapeutics. However, anti-invasive agents would help to limit tertiary spread, metastases from metastasis, a process that clearly has significant impact on patient morbidity. ${ }^{140}$ Following surgical debulking of a glioblastoma, inhibition of further infiltration by remaining tumour cells into surgically inaccessible or "eloquent" areas such as the motor- or speech-regions may represent an important contribution to patient-outcome. Furthermore, protease inhibitors affect not only invasiveness, but impact upon other facets of glioma biology, including growth and angiogenesis. ${ }^{123-127}$ In this way, MMP inhibitors may limit the growth of micro-invasive lesions that require an angiogenic response for macroscopic development. Used in this way, MMP inhibitors may represent potential agents to complement cytotoxic therapies.

\section{Conclusions}

Despite many therapeutic strategies undertaken in the treatment of glioblastoma multiforme, the survival rate for patients afflicted with this aggressive cerebral malignancy remains poor. ${ }^{15}$ Even with combinations of different therapeutic modalities, a good prognosis is extremely rare, as remaining cells infiltrating the normal brain tissue inevitable lead to tumour recurrence. ${ }^{14}$ The invasive process thus constitutes the most lethal property of high grade gliomas and is therefore a necessary focus of further research.

As proteases constitute the final effectors of tumour invasiveness, they, as well as their upstream regulators, represent viable targets for anti-invasive therapeutics. Modulation of MMP activity may impact upon the malignant phenotype of glioblastomas in several ways. First, they may block invasion. Second, blockade of protease function can change tumour growth characteristics by effectively altering the tumour's interaction with the ECM. Third, inhibition of angiogenesis may limit tumour size to a microscopic mass, making it more difficult for the tumour to overwhelm cytotoxic agents.

Synthetic inhibitors of MMPs as well agents that target upstream regulators of MMPs, such as PKC inhibitors, have shown promise in vitro and in vivo as potential therapeutic agents. With further refinements, such agents will hopefully become important complements to other chemotherapeutic regimens. However, despite their demonstrated efficacy, it is likely too optimistic and naive to believe that they will lead to a cure for malignant brain tumours. While such agents may not be able to achieve a "cure," extended prolongation of survival afforded by the blockade of tumour infiltration and growth by anti-invasive agents will hopefully be successful in converting this lethal disease into more of a "chronic disease" with which the patient may be able to live longer. While it may represent a compromise, the potential benefit for patient-outcome will be greatly welcomed.

\section{ACKNOWLEDGEMENTS}

This article is based, in part, on work which was presented at the Canadian Congress of Neurological Sciences (30th Annual Meeting, Victoria, British Columbia), at which time JHU was awarded the André Barbeau Memorial Prize. We thank the Canadian Neurological Society for support of residents' research through the sponsorship of awards such as the Andre Barbeau Prize. We would also like to thank the Brain Tumour Foundation of Canada and the Cancer Research Society, Inc. for support of operational funds.

\section{REFERENCES}

1. Dedhar S. Integrins and tumor invasion. BioEssays 1990; 12: 583590.

2. Ruoslahti $\mathrm{E}$. Control of cell motility and tumour invasion by extracellular matrix interactions. Br J Cancer 1992; 66: 239-242.

3. Furcht LT, Skubitz AP, Fields GB. Tumor cell invasion, matrix metalloproteinases, and the dogma [editorial; comment]. Lab Invest 1994; 70: 781-783.

4. Stetler-Stevenson WG, Liotta LA, Kleiner DE, Jr. Extracellular matrix 6: role of matrix metalloproteinases in tumor invasion and metastasis. FASEB J 1993; 7: 1434-1441.

5. Mignatti P, Rifkin DB. Biology and biochemistry of proteinases in tumor invasion. Physiol Rev 1993; 73: 161-195.

6. MacDougall JR, Matrisian LM. Contributions of tumor and stromal matrix metalloproteases to tumor progression, invasion and metastasis. Cancer and Metast Rev 1995; 14: 351-362.

7. DeClerck YA, Yean TD, Chan D, Shimada H, Langley, KE. Inhibition of tumor invasion of smooth muscle cell layers by recombinant human metalloproteinase inhibitor. Cancer Res 1991; 51: 2151-2157.

8. Vaithilingam IS, McDonald W, Brown NK, et al. Serum proteolytic activity during the growth of C6 astrocytoma. J Neurosurg 1992; 77: $595-600$

9. Nakagawa T, Kubota T, Kabuto M, et al. Production of matrix metalloproteinases and tissue inhibitor of metalloproteinases- 1 by human brain tumors. J Neurosurg 1994; 81: 69-77.

10. Del Maestro RF, Lopez-Torres M, McDonald WB, et al. The effect of tumor necrosis factor- $\alpha$ on human malignant glial cells. $J$ Neurosurg 1992; 76: 652-659.

11. Yamamoto M, Sawaya R, Mohanam S, et al. Expression and cellular localization of messenger RNA for plasminogen activator inhibitor type 1 in human astrocytomas in vivo. Cancer Res 1994; 54: 3329-3332.

12. Rao JS, Steck PA, Mohanam S, Stetler-Stevenson WG, Liotta LA. Elevated levels of Mr 92,000 Type IV collagenase in human brain tumors. Cancer Res 1993; 53: 2208-2211.

13. Rao JS, Steck PA, Tofilon P, et al. Role of plasminogen activator and of 92-KDa type IV collagenase in glioblastoma invasion using an in vitro matrigel model. J Neurooncol 1994; 18: 129138.

14. Couldwell WT, de Tribolet N, Antel JP, Gauthier T, Kuppner MC. Adhesion molecules and malignant gliomas: implications for tumorigenesis. J Neurosurg 1992; 76: 782-791.

15. Berens ME, Rutka JT, Rosenblum ML. Brain tumor epidemiology, growth, and invasion. Neurosurg Clin North Am 1990; 1: 1-18.

16. Barker FG II, Israel MA. The molecular biology of brain tumors. Neurol Clin 1995; 13: 701-722.

17. Wang X, Fu X, Brown PD, Crimmin MJ, Hoffman RM. Matrix metalloproteinase inhibitor BB-94 (Batimastat) inhibits human colon tumor growth and spread in a patient-like orthotopic model in nude mice. Cancer Res 1994; 54: 4726-4728.

18. Chirivi RGS, Garofalo A, Crimmin MJ, et al. Inhibition of the metastatic spread and growth of B16-B16 murine melanoma by a synthetic matrix metalloproteinase inhibitor. Int J Cancer 1994; 58: 460-464.

19. Taraboletti G, Garofalo A, Belotti D, et al. Inhibition of angiogenesis and murine hemangioma growth by Batimastat, a synthetic inhibitor of matrix metalloproteinases. J Natl Cancer Inst 1995; 87: 293-298.

20. Sledge GWJ, Qulali M, Goulet R, Bone, EA, Fife R. Effect of matrix metalloproteinase inhibitor Batismatat on breast cancer regrowth and metastasis in athymic mice. J. Natl Cancer Inst 1995; 87: 1546-1550.

21. Watson SA, Morris TM, Robinson G, et al. Inhibition of organ invasion by the matrix metalloproteinase inhibitor Batismatat (BB94) in two human colon carcinoma metastasis models. Cancer Res 1995; 55: 3629-3633.

22. Davies B, Brown PD, East N, Crimmin MJ, Balkwill FK. A synthetic metalloproteinase inhibitor decreases tumor burden and prolongs survival of mice bearing human ovarian carcinoma xenografts. Cancer Res 1994; 54: 2087-2091. 
23. Brown PD. Matrix metalloproteinase inhibitors: a novel class of anticancer agents. Adv Enz Regul 1995; 35: 293-301.

24. Moscatelli D, Rifkin DB. Membrane and matrix localization of proteinases: a common theme in tumor cell invasion and angiogenesis. Biochim Biophys Acta 1988; 948: 67-85.

25. Vassalli J-D, Pepper MS. Membrane proteases in focus. Nature 1994; 370: 14-15.

26. Yamamoto M, Sawaya R, Mohanam S, et al. Expression and localization of urokinase-type plasminogen activator in human astrocytomas in vivo. Cancer Res 1994; 54: 3656-3661

27. Mohanam S, Sawaya R, McCutcheon I, et al. Modulation of in vitro invasion of human glioblastoma cells by urokinase-type plasminogen activator receptor antibody. Cancer Res 1993; 53: 4143-4147.

28. Mikkelsen T, Yan P-S, Ho K-L, et al. Immunolocalization of cathep$\sin \mathrm{B}$ in human glioma: implications for tumor invasion and angiogenesis. J Neurosurg 1995; 83: 285-290.

29. Rempel SA, Rosenblum ML, Mikkelsen T, et al. Cathepsin B expression and localization in glioma progression and invasion. Cancer Res 1994; 54: 6027-6031.

30. Matrisian LM The matrix-degrading metalloproteinases. BioEssays 1992; 14: 455-463

31. Jeffrey JJ. Collagen degradation. In: Diegelmann RF, Lindblad WJ, eds. Wound Healing: Biochemical and Clinical Aspects. Philadelphia: WB Saunders Company, 1992: 177-194.

32. Delasse J-M, Vaes G. Mechanism of mineral solubilization and matrix degradation in osteoclastic bone resorption. In: Rifkin BR, Gay CV, eds. Biology and Physiology of the Osteoclast, Boca Raton. FL: CRC Press 1992: 290-314.

33. Liotta LA, Tryggvason K, Garbisa S, et al. Metastatic potential correlates with enzymatic degradation of basement membrane collagen Nature 1980; 284: 67-68.

34. Sato H, Takino T, Okada Y, et al. A matrix metalloproteinase expressed on the surface of invasive tumour cells. Nature 1994; 370: 61-65.

35. Basset $P$, Wolf $C$, Chambon $P$. Expression of the stromelysin- 3 gene in fibroblastic cells of invasive carcinomas of the breast and other human tissues: a review. Breast Cancer Res Treat 1993; 24 : 185-193.

36. Heino J. Biology of tumor cell invasion: interplay of cell adhesion and matrix degradation. Int J Cancer 1996; 65: 717-722.

37. Abe T, Mori T, Kohno K, et al. Expression of $72 \mathrm{kDa}$ type IV collagenase and invasion activity of human glioma cells. Clin Exp Metastasis 1994; 12: 296-304.

38. Apodaca G, Rutka JT, Bouhana K, et al. Expression of metalloproteinases and metalloproteinase inhibitors by fetal astrocytes and glioma cells. Cancer Res 1990; 50: 2322-2329.

39. Uhm JH, Dooley NP, Villemure J-G, Yong, VW. Glioma invasion in vitro: regulation by matrix metalloprotease- 2 and protein kinase C. Clin Exp Metast 1996 14: 421-433.

40. Yamamoto M, Mohanam S, Sawaya R, et al. Differential expression of membrane-type matrix metalloproteinase and its correlation with gelatinase A activation in human malignant brain tumors in vivo and in vitro. Cancer Res 1996; 56: 384-392.

41. Rutka JT, Matsuzawa K, Hubbard SL, et al. Expression of TIMP-1, TIMP-2, 72- and 92-kDa type IV collagenase transcripts in human astrocytoma cell lines: correlation with astrocytoma cell invasiveness. Int J Oncology 1995; 6: 877-884.

42. Sawaya RE, Yamamoto M, Gokaslan ZL, et al. Expression and localization of $72 \mathrm{kDa}$ type IV collagenase (MMP-2) in human malignant gliomas in vivo. Clin Exp Metastasis 1996; 14: 35-42.

43. Takino T, Sato $H$, Shinagawa A, Seiki M. Identification of the second membrane-type matrix metalloproteinase (MT-MMP-2) gene from a human placenta cDNA library. J Biol Chem 1995; 270: 23013-23020

44. Yu M, Sato H, Seiki M. Thompson EW. Complex regulation of membrane-type matrix metalloproteinase expression and matrix metalloproteinase- 2 activation by Concanavalin A in MDA-MB231 human breast cancer cells. Cancer Res 1995; 55: 3272-3277.

45. Lewalle JM, Munaut C, Pichot B, et al. Plasma membrane-dependent activation of gelatinase $\mathrm{A}$ in human vascular endothelial cells. J Cell Physiol 1995; 165: 475-483.
46. Strongin AY, Collier I, Bannikov G, et al. Mechanism of cell surface activation of $72 \mathrm{kDa}$ type IV collagenase: isolation of the activated form of the membrane metalloprotease. J Biol Chem 1995; 270: 5331-5338.

47. Matrisian LM. Matrix metalloproteinase gene expression. Ann NY Acad Sci 1994; 732: 42-50.

48. Hu E, Mueller E, Oliviero S, et al. Targeted disruption of the c-fos gene demonstrates c-fos-dependent and -independent pathways for gene expression stimulated by growth factors or oncogenes. EMBO J 1994; 13: 3094-3103.

49. Wasylyk C, Flores P, Gutman A, Wasylyk B. PEA3 is a nuclear target for transcription activation by non-nuclear oncogenes. EMBO J 1989; 8: 3371-3378.

50. von Deimling A, Louis DN, Wiestler OD. Molecular pathways in the formation of gliomas. Glia 1995; 15: 328-338.

51. Collins VP. Gene amplification in human gliomas. Glia 1995; 15 : 289-296.

52. Cavenee WK, White RL. The genetic basis of cancer. Sci Am 1995; 272: $72-79$.

53. Dalrymple SJ, Jenkins RB. Molecular genetics of astrocytomas and meningiomas. Curr Opin Neurol 1994; 7: 477-483.

54. Lund-Johansen M, Bjerkvig R, Humphrey P, et al. Effect of epider$\mathrm{mal}$ growth factor on glioma cell growth, migration, and invasion in vitro. Cancer Res 1990; 50: 6039-6044.

55. Lund-Johansen M, Forsberg K, Bjerkvig R, Laerum OD. Effects of growth factors on a human cell line during invasion into rat brain aggregates in culture. Acta Neuropathol 1992; 84: 190-197.

56. Engerbraaten O, Bjerkvig R, Pedersen P-H, Laerum OD. Effects of EGF, bFGF, NGF and PDGF(bb) on cell proliferative, migratory, and invasive capacities of human brain-tumour biopsies in vitro. Int J Cancer 1993 53: 209-214.

57. Pedersen PH, Ness GO, Engebraaten O, et al. Heterogenous response to the growth factors [EGF, PDGF(bb), TGF-alpha, bFGF, IL-2] on glioma spheroid growth, migration and invasion. Int J Cancer 1994; 56: 255-261.

58. Takahashi JA, Fukumoto M, Igarshi K, et al. Correlation of basic fibroblast growth factor expression levels with the degree of malignancy and vascularity in human gliomas. J Neurosurg 1992; 76: 792-798.

59. Takahashi JA, Mori H, Fukumoto $M$, et al. Gene expression of fibroblast growth factors in human gliomas and meningiomas: demonstration of cellular source of basic fibroblast growth factor mRNA and peptide in tumor tissues. Proc Natl Acad Sci USA 1990; 87: 5710-5714.

60. Zagzag D, Miller DC, Sato Y, Rifkin DB, Burstein DE. Immunohistochemical localization of basic fibroblast growth factor in astrocytomas. Cancer Res 1990; 50: 7393-7398.

61. Morrison RS, Yamaguchi F, Saya $\mathrm{H}$, et al. Basic fibroblast growth factor and fibroblast growth factor receptor I are implicated in the growth of human astrocytomas. J Neurooncol 1994; 18: 207 216.

62. Ueba T, Takahashi JA, Fukumoto M, et al. Expression of fibroblast growth factor receptor- 1 in human glioma and meningioma tissues. Neurosurgery 1994; 34: $221-225$.

63. Chicoine MR, Madsen CL, Silbergeld DL. Modification of human locomotion in vitro by cytokines EGF, bFGF, PDGFbb, NGF, and TNF alpha. Neurosurgery 1995; 36: 1165-1170.

64. Gately S, Tsanaclis AM, Takano S, Klagsbrun M, Brem S. Cells transfected with the basic fibroblast growth factor gene fused to a signal sequence are invasive in vitro and in situ in the brain. Neurosurgery 1995; 36: 780-788.

65. Nerlov C, Rorth P, Blasi F, Johansen M. Essential AP-1 and PEA3 binding elements in the human urokinase enhancer display cell type-specific activity. Oncogene 1991; 6: 1583-1592.

66. Flaumenhaft R, Moscatelli D, Saksela O, Rifkin DB. Role of extracellular matrix in the action of basic fibroblast growth factor: matrix as a source of growth factor for long-term stimulation of plasminogen activator production and DNA synthesis. J Cell Physiol 1989; 140: 75-81.

67. Landau BJ, Kwaan HC, Verrusio EN, Brem SS. Elevated levels of urokinase-type plasminogen activator and plasminogen activator inhibitor type-1 in malignant human brain tumors. Cancer Res 1994; 54: 1105-1108. 
68. Rucklidge GJ, Edvardsen K, Bock E. Cell-adhesion molecules and metalloproteinases: a linked role in tumour cell invasiveness. Biochem Soc Trans 1994; 22: 63-68.

69. Levy AT, Cioce V, Sobel ME, et al. Increased expression of the $M_{r}$ 72,000 type IV collagenase in human colonic adenocarcinoma. Cancer Res 1991; 51: 439-444.

70. Overall CM, Wrana JL, Sodek J. Transcriptional and post-transcriptional regulation of $72-\mathrm{kDa}$ gelatinase/type IV collagenase by transforming growth factor-beta 1 in human fibroblasts. Comparisons with collagenase and tissue inhibitor of matrix metalloproteinase gene expression. J Biol Chem 1991; 266: 14064-14071

71. Sato H, Seiki M. Membrane-type matrix metalloproteinases (MTMMPs) in tumor metastasis. J Biochem 1996; 119: 209-215.

72. Tokuraku M, Sato H, Murakami S, et al. Activation of the precursor of gelatinase $\mathrm{A} / 72 \mathrm{kDa}$ type IV collagenase/MMP-2 in lung carcinomas correlates with the expression of membrane-type metalloproteinase (MT-MMP) and with lymph node metastasis. Int J Cancer 1995; 64: 355-359.

73. Nomura H, Sato H, Seiki M, Mai M, Okada Y. Expression of membrane-type matrix metalloproteinase in human gastric carcinomas. Cancer Res 1995; 55: 3263-3266.

74. Foda HD, George S, Conner C, et al. Activation of human umbilical vein endothelial cell progelatinase $A$ by phorbol myristate acetate: a protein kinase $C$-dependent mechanism involving a membrane-type matrix metalloproteinase. Lab Invest 1996; 74: 538-545

75. Yamada $T$, Yoshiyama $Y$, Sato $H$, et al. White matter microglia produce membrane-type matrix metalloprotease, an activator of gelatinase A, in human brain tissues. Acta Neuropathol 1995; 90: $421-424$

76. Boone TC, Johnson MJ, DeClerck YA, Langley KE. cDNA cloning and expression of a metalloproteinase inhibitor related to tissue inhibitor of metalloproteinases. Proc Natl Acad Sci USA 1990; 87: 2800-2804.

77. DeClerck YA, Yean TD, Ratzkin, BJ, Lu HS, Langley KE. Purification and characterization of two related but distinct metalloproteinase inhibitors secreted by bovine aortic endothelial cells. J Biol Chem 1989; 264: 17445-17453.

78. Murphy G, Cawston T, Reynolds J. An inhibitor of collagenase from human amniotic fluid: purification, characterization and action on metalloproteinases. Biochem J 1981; 195: 167-170.

79. Stetler-Stevenson WG, Krutzsch HC, Liotta LA. Tissue inhibitor of metalloproteinase (TIMP-2): a new member of the metalloproteinase inhibitor family. J Biol Chem 1989; 264: 1737417378.

80. Goldberg GI, Marmer BL, Grant GA, et al. Human $72 \mathrm{~K}$ type IV collagenase forms a complex with a tissue inhibitor of metalloproteinases designated TIMP-2. Proc Natl Acad Sci USA 1989; 86: 8207-8211.

81. Goldberg GI, Strongin A, Collier IE, Genrich LT, Marmer BL. Interaction of $92-\mathrm{kDa}$ type IV collagenase with the tissue inhibitor of metalloproteinase prevents dimerization, complex formation with interstitial collagenase and activation of the proenzyme with stromelysin. J Biol Chem 1992; 267: 45834591.

82. DeClerck YA, Imren S. Protease inhibitors: role and potential therapeutic use in human cancer. Eur J Cancer 1994; 30A: 2170 2180 .

83. Matsuzawa K, Fukuyama K, Hubbard SL, Dirks PB, Rutka JT. Transfection of an invasive human astrocytoma cell line with a TIMP-1 CDNA: modulation of astrocytoma invasive potential. J Neuropathol Exp Neurol 1996; 55: 88-96.

84. Nakano A, Tani E, Miyazaki K. Yamamoto Y, Furuyama J-I. Matrix metalloproteinases and tissue inhibitors of metalloproteinases in human gliomas. J Neurosurg 1995; 83: 298-307.

85. DeClerck YA, Perez N, Shimada H, et al. Inhibition of invasion and metastasis in cells transfected with an inhibitor of metalloproteinases. Cancer Res 1992; 52: 701-708.

86. Mohanam S, Wang SW, Rayford A, et al. Expression of tissue inhibitors of metalloproteinases: negative regulators of human glioblastoma invasion in vivo. Clin Exp Metastasis 1995; 13: 5762 .
87. Kossakowska AE, Urbanski SJ, Edwards DR. Tissue inhibitor of metalloproteinases-1 (TIMP-1) RNA is expressed at elevated levels in malignant non-Hodgkin's lymphomas. Blood 1991; 77: 2475-2481.

88. Kossakowska AE, Urbanski SJ, Watson A, Hayden LJ, Edwards DR. Patterns of expression of metalloproteinases and their inhibitors in human malignant lymphomas. Oncol Res 1993; 5: 19-28.

89. Visscher DW, Hoyhtya M, Ottosen SK, et al. Enhanced expression of tissue inhibitor of metalloproteiase-2 (TIMP-2) in the stroma of breast carcinoma correlates with tumour recurrence. Int $\mathrm{J}$ Cancer 1994; 59: 339-344.

90. Fridman R, Bird RE, Hoyhtya M, et al. Expression of human recombinant $72 \mathrm{kDa}$ gelatinase and tissue inhibitor of metalloproteinase-2 (TIMP-2): characterization of complex and free enzyme. Biochem J 1993; 289: 411-416.

91. Gasson JC, Golde DW, Kaufman SE, et al. Molecular characterization and expression of the gene encoding human erythroidpotentiating activity. Nature 1985; 315: 768-771.

92. Stetler-Stevenson WG, Bersch N, Golde DE. Tissue inhibitor of metalloproteinase-2 (TIMP-2) has erythroid potentiating activity. FEBS Lett 1992; 296: 231-234.

93. Avalos BR, Kaufman SE, Tomonaga M, et al. K562 cells produce and respond to human erythroid-potentiating activity. Blood 1988; 71: 1720-1725.

94. Bertaux B, Hornebeck W, Eisen AZ, Dubertret L. Growth stimulation of human keratinocytes by tissue inhibitor of metalloproteinases. J Invest Dermatol 1991; 97: 679-685.

95. Hayakawa T, Yamashita K, Tanzawa K, Uchijima E, Iwata K. Growth-promoting activity of tissue inhibitor of metalloproteinases-1 (TIMP-1) for a wide range of cells. FEBS Lett 1992; 298: 29-32

96. Murate T, Yamashita K, Ohashi H, et al. Erythroid potentiating activity of tissue inhibitor of metalloproteinases on the differentiation of erythropoietin-responsive mouse erythroleukemia cell line, ELM-I-1-3, is closely related to its cell growth potentiating activity. Exp Hematol 1993; 21: 169-176.

97. Nemeth JA, Goolsby, CL. TIMP-2, a growth-stimulatory protein from SV40-transformed human fibroblasts. Exp Cell Res 1993; 207: 376-382.

98. Overall CM. Regulation of tissue inhibitor of matrix metalloproteinase expression. In: Greenwald RA and Golub LM, eds. Inhibition of Matrix Metalloproteinases: Therapeutic Potential. New York: The New York Academy of Sciences, 1994: 51-64.

99. Weinstein IB. The role of protein kinase $C$ in growth control and the concept of carcinogenesis as a progressive disorder in signal transduction. Adv in Second Messenger Phosphoprotein Res 1990; 24: 307-316.

100. Schwartz GK, Jiang J, Kelsen D, Albino AP. Protein kinase C: a novel target for inhibiting gastric cancer cell invasion. J Natl Cancer Inst 1994; 85: 402-407.

101. Baltuch GH, Dooley NP, Rostworowski KM, Villemure J-G, Yong VW. Protein kinase $\mathrm{C}$ isoform $\alpha$ overexpression in C6 glioma cells and its role in cell proliferation. J Neurooncol 1995; 24: 24l-250.

102. Baltuch GH, Dooley NP, Villemure J-G, Yong VW. Protein kinase $\mathrm{C}$ and growth regulation of malignant gliomas. Can J Neurol Sci 1995; 22: 264-271.

103. Baltuch GH, Dooley NP, Couldwell WT, Yong VW. Staurosporine differentially inhibits glioma versus non-glioma cell lines. J Neurooncol 1993; 16: 141-147.

104. Couldwell WT, Antel JP, Apuzzo MLJ, Yong VW. Inhibition of growth of established human glioma lines by modulators of the protein kinase C system. J Neurosurg 1990; 73: 594-600.

105. Couldwell WT, Uhm JH, Antel JP, Yong VW. Enhanced protein kinase $\mathrm{C}$ activity correlates with the growth rate of malignant gliomas in vitro. Neurosurgery 1991;29: 880-887.

106. Couldwell WT, Antel JP, Yong VW. Protein kinase C (PKC) activity correlates with growth rate of gliomas. II: Effects of glioma mitogens and modulators of PKC. Neurosurgery 1992; 31: 717 724.

107. Ahmad S, Mineta T, Martuza RL, Glazer RI. Antisense expression of protein kinase $\mathrm{C} \alpha$ inhibits the growth and tumorigenicity of human glioblastoma cells. Neurosurgery 1994; 35: 904-909. 
108. Glazer RI, Ahmad S, Yazaki T, Martuza RL, Dean N. Inhibition of glioblastoma $\mathrm{U}-87$ in vivo by a protein kinase $\mathrm{C} \alpha(\mathrm{PKC} \alpha)$ antisense phosphorothioate oligodeoxynucleotide (S-oligo). Proc Am Assoc Cancer Res 1996; 37: (Abstract).

109. Gopalakrishna R, Barsky SH. Tumor promoter-induced membrane-bound kinase $\mathrm{C}$ regulates hematogenous metastasis. Proc Natl Acad Sci USA 1988; 85: 612-616.

110. Takenaga K, Takahashi K. Effects of 12-O-tetradecanylphorbol-13acetate on adhesiveness and lung-colonizing ability of Lewis lung carcinoma cells. Cancer Res 1986; 40: 375-380.

111. Korczak B, Whale C, Kerbel RS. Possible involvement of $\mathrm{Ca}^{2+}$ mobilization and protein kinase $\mathrm{C}$ activation in the induction of spontaneous metastasis by mouse mammary adenocarcinoma cells. Cancer Res 1989; 49: 2597-2602.

112. Nabeshima K, Komada N, Kishi J, et al. TPA-enhanced invasion of matrigel associated with augmentation of cell motility but no metalloproteinase activity in a highly metastatic variant (L-10) of human rectal adenocarcinoma cell line RCM-1. Int J Cancer 1993; 55: 974-981.

113. Schwartz GK, Redwood SM, Ohnuma T, et al. Inhibition of invasion of invasive human bladder carcinoma cells by protein kinase C inhibitor staurosporine. J Natl Cancer Inst 1990; 82: 17531756.

114. Lamph WW, Wamsley P, Sassone-Corsi P, Verma IM. Induction of proto-oncogene jun/AP-1 by serum and TPA. Nature 1988; 334 : 629-631.

115. Overall CM, Sodek J. Concanavalin A produces a matrix-degradative phenotype in human fibroblasts. Induction and endogenous activation of collagenase, $72-\mathrm{kDa}$ gelatinase, and Pump-1 is accompanied by the suppression of the tissue inhibitor of matrix metalloproteinases. J Biol Chem 1990; 265: 21141-21151.

116. Lim Y-T, Sugiura Y, Laug WE, et al. Independent regulation of matrix metalloproteinases and plasminogen activators in human fibrosarcoma cells. J Cell Physiol 1996; 167: 333-340.

117. DiBattista JA, Pelletier JP, Zafarullah M, et al. Coordinate regulation of matrix metalloproteases and tissue inhibitor of metalloproteinase expression in human synovial fibroboasts. J Rheumatol 1995; 43 (Suppl): 123-128.

118. Ries C, Kolb H, Petrides PE. Regulation of $92-\mathrm{kD}$ gelatinase release in HL-60 leukemia cells: tumor necrosis factor-alpha as an autocrine stimulus for basal- and phorbol ester-induced secretion. Blood 1994; 83: 3638-3646.

119. Juarez J, Clayman G, Nakajima M, et al. Role and regulation of expression of 92-kDa type-IV collagenase (MMP-9) in 2 invasive squamous-cell-carcinoma cell lines of the oral cavity. Int $\mathbf{J}$ Cancer 1993; 55: 10-18.

120. Sanz L, Berra E, Municio MM, et al. Zeta PKC plays a critical role during stromelysin promoter activation by platelet-derived growth factor through a novel palindromic element. J Biol Chem 1994; 269: 10044-10049.

121. Nerlov C, Rorth P, Blasi F, Johnsen M. Essential AP-1 and PEA3 binding elements in the human urokinase enhancer display cell type-specific activity. Oncogene 1990; 5: 75-83

122. Honn KV, Timar J, Rozhin J, et al. A lipoxygenase metabolite, 12(S)-HETE, stimulates protein kinase C-mediated release of cathepsin B from malignant cells. Exp Cell Res 1994; 214: 120130.

123. Kent KC, Mii S, Harrington EO, et al. Requirement for protein kinase $\mathrm{C}$ activation in basic fibroblast growth factor-induced human endothelial cell proliferation. Circulation Res 1995; 77 : $231-238$.

124. Hu DE, Fan TP. Protein kinase $C$ inhibitor calphostin $C$ prevents cytokine-induced angiogenesis in the rat. Inflammation 1995; 19: $39-53$
125. Tsopanoglou NE, Haralabopoulos GC, Maragoudakis ME. Opposing effects on modulationof angiogenesis by protein kinase C and cAMP-mediated pathways. J Vase Res 1994; 31 : 195-204.

126. Davis CM, Danehower SC, Laurenza A, Molony JL. Identification of a role of the vitronectin receptor and protein kinase $C$ in the induction of endothelial cell vascular formation. J Cell Biochem 1993; 51: 206-218.

127. Stanimirovic DB, Ball R, Durkin JP. Evidence for the role of protein kinase $\mathrm{C}$ in astrocyte-induced proliferation of rat cerebromicrovascular endothelial cells. Neurosci Lett 1995; 197: 219-222.

128. Couldwell WT, Hinton DR, He SK, et al. Protein kinase C inhibitors induce apoptosis in human malignant glioma cell lines. FEBS Lett 1994; 345: 43-46.

129. Ikemoto H, Tani E, Matsumoto T, Nakano A, Furuyama J-I. Apoptosis of human glioma cells in response to calphostin $\mathrm{C}$, a specific protein kinase C inhibitor. J Neurosurg 1995; 83: 10081016.

130. Dooley NP, Baltuch GH, Groome N, Villemure J-G, Yong, VW. Apoptosis is induced in A172 human glioma line by antisense oligonucleotides to protein kinase $\mathrm{C} \alpha$ and is enhanced by cycloheximide (submitted).

131. Basu A. The potential of protein kinase $\mathrm{C}$ as a target for anticancer treatment. Pharmac Ther 1993; 59: 257-280.

132. Baltuch G, Shenouda G, Langleben A, Villemure J-G. High-dose tamoxifen in the treatment of recurrent high grade glioma: a report of clinical stabilization and tumour regression. Can J Neurol Sci 1993; 20: 168-170.

133. Bradshaw D, Hill CH, Nixon JS, Wilkinson SE. Therapeutic potential of protein kinase C inhibitors. Agents Actions 1993; 38: 135-147.

134. Couldwell WT, Hinton DR, Surnock AA, et al. Treatment of recurrent malignant gliomas with chronic oral high-dose tamoxifen. Clin Cancer Res 1996; 2: 619-622

135. Baltuch GH, Couldwell WT, Villemure J-G, Yong, VW. Protein kinase $\mathrm{C}$ inhibitors suppress cell growth in established and low passage glioma cell lines. A comparison between staurosporine and tamoxifen. Neurosurgery 1993; 33: 495-501.

136. O'Brian CA, Liskamp RM, Solomon DH, Weinstein IB. Inhibition of protein kinase C by tamoxifen. Cancer Res 1985; 45: 2462 2465.

137. Pollack IF, Randall MS, Kristofic MP, et al. Effect of tamoxifen on DNA synthesis and proliferation of human malignant glioma lines in vitro. Cancer Res 1990; 50: 7134-7138.

138. Couldwell WT, Weiss MH, DeGiorgio CM, et al. Clincal and radiographic response in a minority of patients with recurrent malignant gliomas treated with high-dose tamoxifen. Neurosurgery $1993 ; 32: 485-490$.

139. Brown PD. Synthetic matrix metalloproteinase inhibitors: From cancer models to cancer patients. Proc Am Assoc Cancer Res 1996; 37: 633-634.

140. Crissman J Metastases from metastasis: clinical relevance in human cancer. In: Goldfarb R, ed. Fundamental Aspects of Cancer. Dordrecht, Netherlands: Kluwer Academic Publishers, 1989: 156-161.

141. Kono S, Sci DM, Rao JS, Bruner JM, Sawaya R. Immunohistochemical localization of plasminogen activator inhibitor type 1 in human brain tumors. J Neuropathol Exp Neurol 1994; 53: 256-262.

142. Vaithilingam IS, McDonald W, Malott DW, Del Maestro RF. An extracellular proteasome-like structure from C6 astrocytoma cells with serine collagenase IV activity and metallo-dependent activity on $\alpha$-casein and $\beta$-insulin. J Biol Chem 1995; 270: 4588-4593.

143. Woessner JF, Jr. The family of matrix metalloproteinases. Ann NY Acad Sci 1994; 732: 11-21. 